\title{
NuMA distribution and microtubule configuration in rabbit oocytes and cloned embryos
}

\author{
Li-Ying Yan ${ }^{1,2}$, Jun-Cheng Huang ${ }^{1,2}, \mathrm{Zi}-\mathrm{Yu} \mathrm{Zhu}^{3}$, Zi-Li Lei ${ }^{1,2}, \mathrm{Li}_{\text {-Hong Shi }}{ }^{1,2}$, Chang-Long Nan ${ }^{1,2}$, \\ Zhen-Jun Zhao ${ }^{1,2}$, Ying-Chun OuYang ${ }^{1}$, Xiang-Fen Song ${ }^{1}$, Qing-Yuan Sun ${ }^{1}$ and Da-Yuan Chen ${ }^{1}$ \\ ${ }^{1}$ State Key Laboratory of Reproductive Biology, Institute of Zoology, Chinese Academy of Sciences, 25 Beisihuanxi \\ Road, Haidian, Beijing 100080, China, ${ }^{2}$ Graduate School, Chinese Academy of Sciences, Beijing 100080, China and \\ ${ }^{3}$ College of Life Science, Soochow University, Suzhou 215006, China
}

Correspondence should be addressed to D-Y Chen; Email: chendy@ioz.ac.cn

\begin{abstract}
The assembly of microtubules and the distribution of NuMA were analyzed in rabbit oocytes and early cloned embryos. $\alpha$-Tubulin was localized around the periphery of the germinal vesicle (GV). After germinal vesicle breakdown (GVBD), multi-arrayed microtubules were found tightly associated with the condensed chromosomes and assembled into spindles. After the enucleated oocyte was fused with a fibroblast, microtubules were observed around the introduced nucleus in most reconstructed embryos and formed a transient spindle 2-4 h post-fusion (hpf). A mass of microtubules surrounded the swollen pseudo-pronucleus $5 \mathrm{hpf}$ and a normal spindle was formed $13 \mathrm{hpf}$ in cloned embryos. NuMA was detected in the nucleus in germinal vesicle-stage oocytes, and it was concentrated at the spindle poles in both meiotic and mitotic metaphase. In both donor cell nucleus and enucleated oocyte cytoplasm, NuMA was not detected, while NuMA reappeared in pseudo-pronucleus as reconstructed embryo development proceeded. However, no evident NuMA staining was observed in the poles of transient spindle and first mitotic spindle in nuclear transfer eggs. These results indicate that NuMA localization and its spindle pole tethering function are different during rabbit oocyte meiosis and cloned embryo mitosis. Reproduction (2006) 132 869-876
\end{abstract}

\section{Introduction}

Since the first cloned mammals were produced (Wilmut et al. 1997), many species have been cloned by somatic cell nuclear transfer (SCNT). There were some reports on rabbits cloning, but only until 2002, the cloned rabbits derived by SCNT were successfully born (Chesne et al. 2002). After the introduction of $\mathrm{G}_{0}$-phase somatic cell into a mature oocyte, the reconstructed embryo undergoes nuclear membrane breakdown and chromosome condensation, followed by metaphase spindle-like structure formation, but most of these embryos ceased development afterwards due to possible defective chromatin remodeling and abnormal microtubule organization (Wakayama et al. 2000, Mir et al. 2003, Zhong et al. 2005, Yan et al. 2006).

NuMA (a nuclear protein that associates with the mitotic apparatus) is an abundant $235 \mathrm{kDa}$ protein that is localized to the nucleus during interphase and accumulates at the spindle poles during mitosis. NuMA is associated with dynein/dynactin and spindle poles in extracts and cultured cells. Disruption of NuMA function by antibody injection or immunodepletion in extracts demonstrated that NuMA is required for the assembly and maintenance of spindle poles (Kallajoki et al. 1991, Yang \& Snyder 1992, Gaglio et al. 1995, Merdes et al. 1996, Gordon et al. 2001). In dividing cells, upon phosphorylation, NuMA disperses into the cytoplasm, associates with cytoplasmic dynein/dynactin to form a complex. NuMA's function in spindle microtubule organization is regulated by RanGTP and Pins-related protein. It has been shown that phosphorylation of NuMA is by cyclin B/cdc2 kinase and NuMA's dephosphorylation is due to the cyclin B degradation. NuMA also functions during meiotic spindle organization in male and female germ cells (see reviews by Zeng 2000, Sun \& Schatten 2006).

In previous studies, the researchers analyzed the expression pattern and function of NuMA in mouse and pig oocytes (Lee et al. 2000) and early embryos (Tang et al. 2004) as well as mouse (Zhong et al. 2005, Van Thuan et al. 2006) and pig (Liu et al. 2006) cloned embryos. But the dynamic changes of NuMA and microtubules during meiosis I-II transition in rabbit oocytes have not been reported. Further, the spindle formation and NuMA distribution in early rabbit cloned embryos have not been observed. 
In this study, we observed the dynamic changes of NuMA, chromatin, and microtubules during rabbit oocyte maturation and the first cell cycle progression of cloned rabbit embryos.

\section{Materials and Methods}

\section{Animals}

Animal care and handling were in accordance with the policy on the Care and Use of Animals of the Ethical Committee, Institute of Zoology, Chinese Academy of Sciences. Female big-eared Japan white rabbits (purchased from Laboratory Animal Center, Institute of Zoology, Chinese Academy of Sciences) were housed in stainless steel cages and were fed with regular rabbit fodder and water ad libitum.

\section{Oocyte collection}

Mature female rabbits were superovulated by administering pregnant mares serum gonadotrophin (PMSG) and human chorionic gonadotropin (hCG) (Institute of Zoology, Chinese Academy of Sciences). Each rabbit was injected with 100 IU PMSG and 100 IU hCG $96 \mathrm{~h}$ later. At $14 \mathrm{~h}$ after hCG treatment, the females were laparotomized. Ovaries were then removed and minced in M199 and oocytes were isolated by mouth pipette. Since the rabbits were treated by superovulation, we could get oocytes at different maturation stages from the ovaries without culture in vitro. Oocytes without cumulus cells were fixed directly. Matured metaphase II stage (MII) rabbit oocytes were flushed from the oviducts with warm 199 medium (Gibco BRL, NY).

All oocytes were treated shortly with $300 \mathrm{IU} / \mathrm{ml}$ hyaluronidase (Sigma Chemical Co) in M199 medium at $37^{\circ} \mathrm{C}$. Cumulus cells were stripped from the oocytes by repeated gentle pipetting. Rabbit oocytes at germinal vesicle (GV) stage were freed of cumulus cells by repeated pipetting with a pipette, whose diameter was a little smaller than the oocyte.

\section{Oocyte enucleation}

The cumulus-free MII eggs were transferred to M199 medium containing $7.5 \mu \mathrm{g} / \mathrm{ml}$ cytochalasin B (Sigma) and $10 \%$ fetal bovine serum (FBS) for $10 \mathrm{~min}$, and then manipulated under an inverted microscope (Nikon's ECLIPSE TE300, Nikon Corporation, Japan). Removal of the meiotic spindle and chromosomes was accomplished in the following way. The 'squish' enucleation method was used for metaphase II spindle aspiration. A cumulusfree oocyte was held with a holding micropipette $(170 \mu \mathrm{m}$ outer diameter, $20 \mu \mathrm{m}$ inner diameter) and the zona pellucida was partially dissected with a fine glass needle to make a slit near the first polar body. The first polar body and adjacent cytoplasm containing the metaphase II spindle were squeezed and extruded with a $20 \mu \mathrm{m}$ pipette gently. After enucleation, the karyoplast was stained with $1 \mu \mathrm{g} / \mathrm{ml}$ Hoechst33342 (Sigma) and exposed to the u.v. light to confirm the removal of chromosomes.

\section{Donor cell preparation}

Fibroblast cells were collected from an ear-skin biopsy of a mature Japanese white female rabbits. Primary cell culture was performed with the same method as described previously (Han et al. 2001). Fibroblasts at passages 4-10 were used as donors.

\section{Cloned rabbit embryo reconstruction}

A single donor cell was introduced into the perivitelline space of an enucleated oocyte. The couplets were preequilibrated in fusion medium consisting of $0.25 \mathrm{M}$ sorbitol, $0.5 \mathrm{mM}$ Hepes, $0.1 \mathrm{mM} \mathrm{Ca}\left(\mathrm{CH}_{3} \mathrm{COO}\right)_{2}$, $0.5 \mathrm{mM} \mathrm{Mg}\left(\mathrm{CH}_{3} \mathrm{COO}\right)_{2}$, and $1 \mathrm{mg} / \mathrm{ml} \mathrm{BSA}$, and then placed between the electrodes of a fusion chamber in fusion medium. Two direct current pulses $(1.4 \mathrm{kV} / \mathrm{cm}$, $80 \mu$ s each, $1 \mathrm{~s}$ apart) were applied with an ECM2001 Electrocell Manipulator (BTX inc., San Diego, CA, USA).

\section{Activation of rabbit oocytes and reconstructed eggs}

Cumulus-free rabbit MII oocytes and fused eggs were transferred to the fusion medium and incubated at room temperature for $1 \mathrm{~min}$, and then transferred to a fusion chamber containing $100 \mu \mathrm{l}$ fusion medium. Activation was achieved by applying double DC pulses of $1.2 \mathrm{kV} / \mathrm{cm}$ for $20 \mu \mathrm{s}$. The activated oocytes and embryos were washed in $\mathrm{M} 199+10 \% \mathrm{FBS}$ at least thrice, and then transferred into the pre-equilibrated culture medium.

\section{Production of in vivo fertilized rabbit embryos}

In vivo fertilized zygotes were collected $18 \mathrm{~h}$ post-hCG from the oviduct ampullae of superovulated females that had been mated with the same strain of males just after hCG injection. After removing cumulus cells with $300 \mathrm{IU} / \mathrm{ml}$ hyaluronidase in M199 medium, zygotes were cultured in M199+10\%FBS. At $30 \mathrm{~h}$ post-hCG, embryos at different stages of mitosis were collected for observation.

\section{Immunofluorescent confocal microscopy}

After removing the zona pellucida in acidic $\mathrm{M}_{2}$ medium ( $\mathrm{pH} 2.5)$, eggs were fixed with $4 \%$ paraformaldehyde in PBS $(\mathrm{pH} 7.4)$ for at least $30 \mathrm{~min}$ at room temperature. Oocytes and reconstructed embryos were permeabilized with $1 \%$ Triton $\mathrm{X}-100$ for $1 \mathrm{~h}$ at $37^{\circ} \mathrm{C}$, followed by blocking in $1 \%$ BSA for $1 \mathrm{~h}$ and incubation for $1 \mathrm{~h}$ at $37^{\circ} \mathrm{C}$ or overnight at $4{ }^{\circ} \mathrm{C}$ with mouse anti-human NuMA 
antibody (Oncogene, EMD Biosciences, San Diego, CA, USA) diluted in the ratio of 1:50 in blocking solution. After washing thrice in PBS containing $0.1 \%$ Tween 20 and $0.01 \%$ Triton X-100 (washing solution) for 5 min each, the oocytes were labeled with fluorescein isothiocyanate (FITC)-conjugated goat anti-mouse IgG diluted in the ratio of $1: 100$ for $1 \mathrm{~h}$ at $37^{\circ} \mathrm{C}$. After extensive washing, DNA of samples was counterstained with propidium iodide. Finally, samples were mounted between a coverslip and a glass slide supported by four columns of a mixture of petroleum jelly and paraffin (9:1). As for microtubule staining, samples were treated exactly the same as those described above except that the first antibody was replaced by monoclonal anti- $\alpha$-tubulinFITC antibody (Sigma).

Digested and dispersed rabbit fibroblasts were placed into Petri dishes containing a cover glass slip, then cultured in Dulbecco's modified Eagle's medium (DMEM)-F12 containing 10\% FBS. When 60-80\% confluence is reached, the cells were fixed. The following immunostaining steps were same as the treatment of reconstructed embryos.

Slides were scanned using Leica TCS4D microscope (Leica Laser Technik, GmbH, Heidelberg, Germany) with an argon/krypton laser at 488 and $563 \mathrm{~nm}$ and two-channel scanning for detection of fluorescein isothiocyanate and phosphatidylinositol respectively.

The distribution patterns of the microtubules, NuMA, and chromosomes were observed at 0.5, 2, 3, 4, 6, 8, 10, 12-13, and $15 \mathrm{~h}$ after fusion. Each experiment was repeated at least thrice and at least ten randomly selected oocytes were examined each time.

\section{Results}

\section{Distribution of NuMA in rabbit fibroblasts}

In rabbit fibroblasts, NuMA was not detected in the nucleus during interphase (Fig. 1A). By prometaphase,
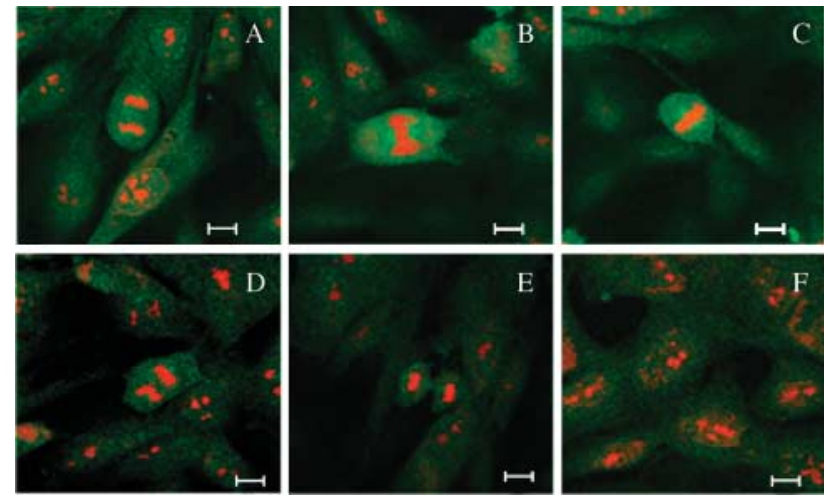

Figure 1 Immunofluorescent localization of NuMA in rabbit during mitosis (A-F). NuMA appears in green and DNA appears in red. Yellow reflects the overlapping of NuMA and DNA images. (A) Interphase, (B) prometaphase, (C) metaphase, (D) anaphase, (E) telophase cytokinesis, (F) serum starvation for 3 days. Bar $=10 \mu \mathrm{m}$.
NuMA appeared in the future spindle poles (Fig. 1B), and located in the spindle poles during metaphase (Fig. 1C). But by late anaphase, the intensity of NuMA staining was decreased in the spindle poles and disappeared from reforming daughter cell nuclei during cytokinesis (Fig. 1D and E). As donor cells in SCNT, fibroblast cells were often treated with serum starvation $(0.5 \%$ FBS $)$ for 3-5 days. In this situation, little NuMA could be detected in the nuclei (Fig. 1F).

\section{Localization of NuMA during rabbit oocyte meiotic maturation, early cleavage of parthenotes, and fertilized embryos}

During meiotic maturation of rabbit oocytes, NuMA was detected either as spots in the nucleus or diffusely spreading across the nucleoplasm (Fig. 2A) at the beginning of germinal vesicle breakdown (GVBD). When chromatin assembled to form chromosome clusters, NuMA distributed as several discrete spots in the vicinity of the condensed chromosomes (Fig. 2B). NuMA surrounded the chromosome clusters in a characteristic crescent shape during prometaphase (Fig. 2C). During both meiotic metaphases I (Fig. 2D) and metaphase II (Fig. 2E) stages, NuMA was localized at the spindle poles.

As for rabbit MII oocyte parthenotes, before the first cell division, NuMA was detected in interphase nucleus $6 \mathrm{~h}$ after electrical activation (Fig. 2F). At the first mitotic prometaphase (Fig. 2G), NuMA was connected with the condensed chromosomes (Fig. $2 \mathrm{H}$ ) and concentrated at the spindle poles during the metaphase. But during the anaphase stage, NuMA disappeared from the poles and scattered into cytoplasm with some small dots (Fig. 2I). When the embryo divides into two cells, NuMA returned to the nucleoplasm (Fig. 2J).

The pattern of NuMA distribution in rabbit fertilized embryos is different from that in parthenotes. NuMA was located in pronucleus (Fig. 2K) or two-cell stage (Fig. 2O) interphase nuclei and then dispersed into cytoplasm during metaphase of the first division (Fig. 2L). However, NuMA cannot be detected during both anaphase (Fig. 2M) and telophase (Fig. 2N).

\section{Distribution of NuMA in rabbit SCNT embryos}

Before enucleation, NuMA was located in the MII spindle poles (Fig. 2E). After enucleation, spindle pole NuMA was removed together with the spindle (Yan et al. 2006). At the first $4 \mathrm{~h}$ post-fusion (hpf), although the donor cell nucleus had undergone premature chromosome condensation (PCC), little NuMA was detected in the reconstructed embryos (Fig. $3 \mathrm{~A}$ ). With the embryo development, NuMA appeared in the newly formed pseudo-pronucleus (Fig. 3B and C) about 5 hpf. After pseudo-pronucleus membrane broke down, NuMA aggregated into some dots near chromosomes (Fig. 3D) 

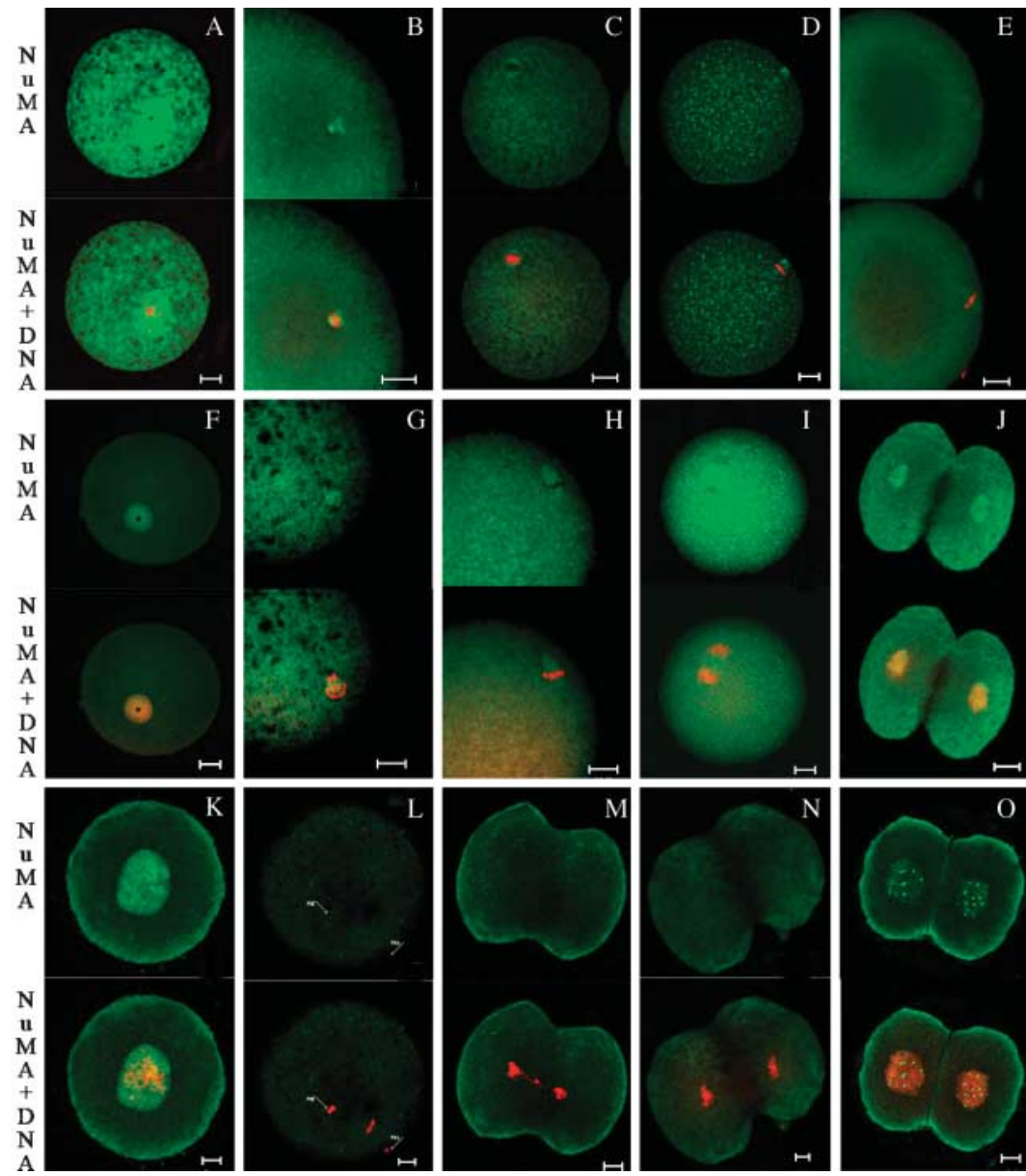

and gradually moved to the whole cytoplasm in numerous green dots at metaphase, anaphase, and telophase (Fig. 3E-G). When the reconstructed embryo cleaved into two cells, NuMA was relocalized in the whole interphase nuclei (Fig. $3 \mathrm{H}$ ).

\section{Microtubule and chromatin dynamics in rabbit oocytes and reconstructed embryos}

Changes in microtubule assembly during rabbit oocyte meiosis were examined using anti-tubulin antibody (Fig. 4). Cytoplasmic microtubules distributed around the periphery of the GV (Fig. 4A). When chromatin was aggregated into a chromosome cluster after GVBD, randomly arrayed microtubules were tightly associated with the chromatin cluster (Fig. 4B). The microtubules organized into two polarized arrays with the axis parallel to the cell surface as chromosomes became aligned on the metaphase plate (Fig. 4C). After first polar body emission, the formation of the meiosis II spindle followed the same process as that for the meiosis I spindle (Fig. 4D and E). During chromosome segregation at anaphase II (Fig. 4F), the spindle elongated and moved to the cell surface.

Microtubule assembly and DNA changes in rabbit reconstructed eggs were examined by fixing the eggs at
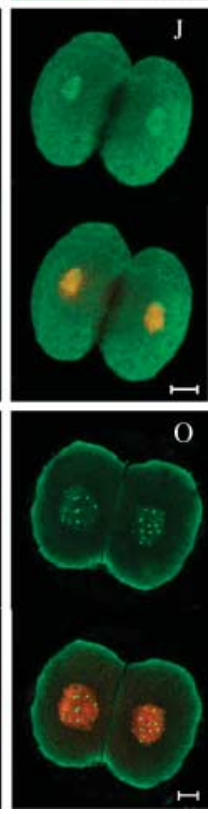
(Fig. 5F-H).

\section{Discussion}

Figure 2 Immunofluorescent localization of NuMA in rabbit meiotic oocytes (A-E), parthenotes $(\mathrm{F}-\mathrm{J})$, and fertilized embryos $(\mathrm{K}-\mathrm{O})$. NuMA appears in green and DNA appears in red. Yellow reflects the overlapping of NuMA and DNA images. (A) GV stage, (B) GVBD stage, (C) prometaphase I stage, (D) metaphase I, (E) metaphase II, (F) 6 h post-activation, (G) first mitotic prometaphase, $(\mathrm{H})$ first mitotic metaphase, (I) anaphase, (J) two-cell stage, (K) pronuclear stage, (L) metaphase of the first division, (M) anaphase, (N) telophase, (O) NuMA was located in two-cell stage interphase nuclei. Bar $=20 \mu \mathrm{m}$.

different time points after the somatic cells were introduced into enucleated oocytes. Minimal change in somatic cell DNA and no microtubule assembly were observed within the first $30 \mathrm{~min}$ after fusion. Within $3-4 \mathrm{~h}$, the PCC was observed in $87 \%$ reconstructed eggs(39/45), and microtubules were assembled into transient spindles (Fig. 5A-C). But at 5-9 hpf, only one pronucleus-like structure could be observed in the majority of embryos (Fig. 5D and E), which was not different from our previous report (Yan et al. 2006) in which the embryos constructed by monkey fibroblast and non-activated enucleated rabbit oocyte formed two pronucleus-like structure following the formation of PCC and spindle organization. During 10-13 hpf, a normal mitotic spindle of the first cell cycle established and reconstructed egg began to undergo cytokinesis

NuMA is a large nuclear protein that accumulates to the spindle poles in mitosis (Lydersen \& Pettijohn 1980), and NuMA is required during mitosis for the terminal phases of chromosome separation and/or nuclear reassembly (Compton \& Cleveland 1993). As the role in meiosis, 

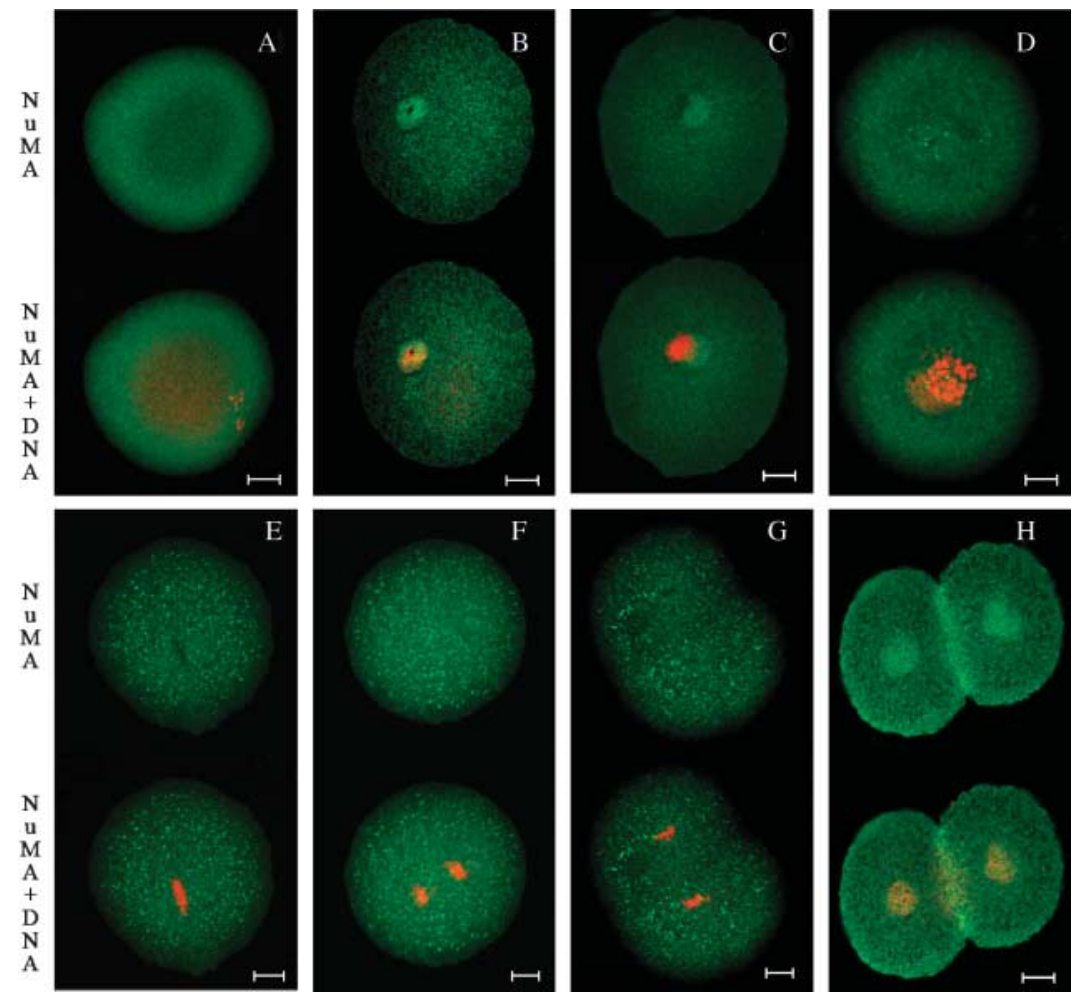

Figure 3 Distribution of NuMA in rabbit SCNT embryos. DNA and NuMA were stained red and green respectively. At $4 \mathrm{~h}$ post-fusion (hpf), donor cell nucleus had undergone PCC and NuMA was not detected between the chromosomes, (B and $\mathrm{C}$ ) 5-9 hpf, NuMA was located in the pseudo-pronucleus, (D) $10 \mathrm{hpf}$, the membrane of pseudo-pronucleus broke down, (E) metaphase of the first division, $(\mathrm{F})$ anaphase, $(\mathrm{G})$ telophase, $(\mathrm{H})$ NuMA was located in two-cell stage interphase nuclei. Bar $=20 \mu \mathrm{m}$.
NuMA appeared to localize to spindle poles of the meiotic pig and mouse oocytes and treatment with nocodazole disrupted the localization of NuMA (Lee et al. 2000). In maturating Xenopus oocytes, the microinjection of NuMA antibodies perturbed the organization of the transient MT array and the meiotic spindle (Becker et al. 2003). But the function of NuMA during interphase is still obscure. There are reports showing that NuMA might organize the chromatin structure (Luderus et al. 1994), others thought that NuMA is a non-essential structural protein of the nucleus, which is preferentially expressed in proliferatively active cells (Merdes \& Cleveland 1998, Taimen et al. 2000). We did not find nuclear localization of NuMA in rabbit fibroblasts whether they were serum starved for 3 days or not. Little NuMA could be observed in interphase nuclei, but a strong expression was observed after the prophase. Evident distribution of NuMA into pole regions of the mitotic spindle was observed. Thus, NuMA may play a role in spindle assembly, but it is not an essential structural nuclear component in rabbit fibroblast cells. In contrast, monkey fibroblasts, even in confluent inhibition status for 3-5 days, contain NuMA in all stages of cell cycle (Yan et al. 2006). The absence of NuMA in rabbit fibroblast could be due to a lack of expression, specific post-translational modifications, or by proteolytic degradation.

During meiotic maturation of rabbit oocytes, NuMA was detected as spots in the nucleus spreading across the nucleoplasm at GV phase or the beginning of GVBD. The NuMA foci were translocated from the condensed chromosomes and became aligned at both poles of the meiotic spindle during the metaphase I and II stages. Comparing with previous studies, we found that NuMA distribution in rabbit species is similar to pig (Lee et al. 2000) but different from mouse (Lee et al. 2000, Tang et al. 2004). In mouse oocytes, NuMA was localized along spindle microtubules (Lee et al. 2000) and at cytasters (Tang et al. 2004).

Although NuMA had not been detected in both donor cell and enucleated oocyte, as embryo development
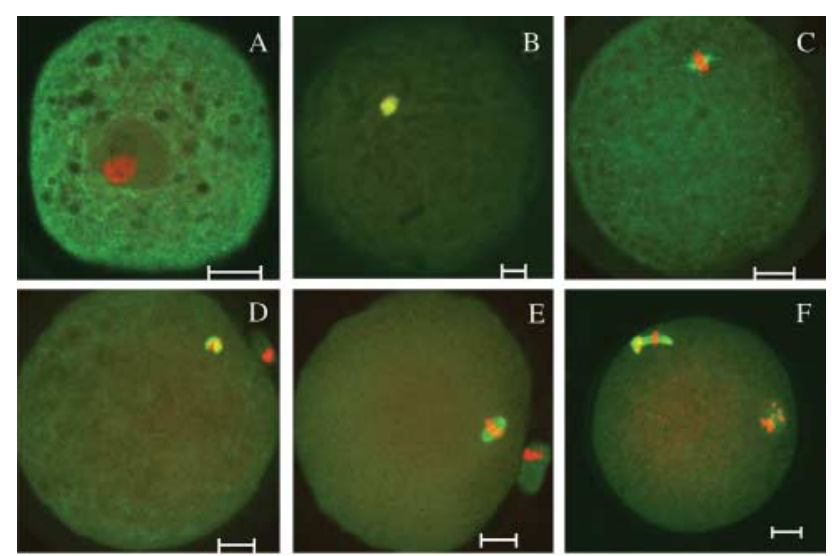

Figure 4 Microtubule organization during rabbit oocyte meiosis. DNA and $\alpha$-tubulin were stained red and green respectively. (A) GV stage, (B) GVBD stage, (C) metaphase I, (D) prometaphase II, (E) metaphase II, (F) anaphase II. Bar $=20 \mu \mathrm{m}$. 

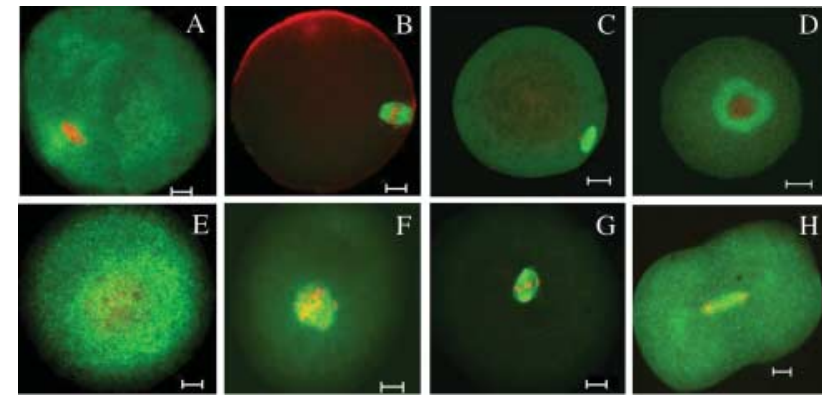

Figure 5 Spindle formation in rabbit reconstructed embryos. DNA and $\boldsymbol{\alpha}$-tubulin were stained red and green respectively. (A) $2 \mathrm{hpf}$, (B) $3 \mathrm{hpf}$, chromosome condensation, (C) 4 hpf, transient spindles formed, (D and E) pseudo-pronucleus formed and a microtubule cluster was assembled around the pseudo-pronucleus at 5-9 hpf, (F) first mitotic prometaphase, (G) first mitotic metaphase $12 \mathrm{hpf}$, (H) first mitotic telophase. Bar $=20 \mu \mathrm{m}$.

proceeded, NuMA reappeared in pseudo-pronucleus during interphase and in cytoplasm during metaphase and anaphase of the first mitotic cell cycle. At first, we regarded the green spots in cytoplasm as non-specific staining. However, such an experiment was repeated eight times and more than 100 cloned embryos $13 \mathrm{hpf}$ were observed, and we found the same phenomenon in all metaphase-stage embryos. In contrast, in other embryos prior to the pronucleus envelope breakdown, little specific NuMA protein was detected in the cytoplasm, although these embryos in different cell cycle phases were fixed at $13 \mathrm{hpf}$ and treated with the same protocol.

These findings raise the question that how NuMA is regulated in the development of rabbit cloned embryos? NuMA expression was influenced by many factors. Spindle pole localization of NuMA requires microtubules and is lost upon treatment of cells with nocodazole (Merdes et al. 1996). When disrupting the function of cytoplasmic dynein or dynactin results in the complete lack of organization of microtubules and the failure to efficiently concentrate the NuMA protein despite its association with the microtubules (Gaglio et al. 1996). However, Heald et al. (1997) thought that dynein is not required for the localization of NuMA to the minus end of MTs.

NuMA is more likely connected to the proliferation phase of the cells (Taimen et al. 2004). For successful nuclear transfer and development of the resulting reconstructed egg, the properties of the donor nucleus have to become like those of the normal zygotic nucleus and the normal kinetics of remodeling occurs during the one-cell stage, and this appears to be the determining factor for the normal onset of gene expression (PintoCorreia et al. 1995, Renard 1998). This procedure requires co-operation of the activities of cell cycle regulators (Fulka et al. 1996) and maternal stores of protein (Almouzni \& Wolffe 1993). It is assumed that the somatic cell nuclei are mysteriously converted to embryonic genomes, which then passively progress down the developmental path leading to a new individual.

Numerous studies in fertilized embryos, however, have made it clear that the embryonic genome is first formed in the zygote, but is then drastically altered to set it on its path of totipotentiality (reviewed in Latham 1999, Latham \& Schultz 2001). Complete reprogramming in cloning seems possible only after remodeling of the donor nucleus, i.e. PCC in non-activated cytoplasm, followed by nuclear swelling upon activation of the oocyte (Bredman et al. 1991). Thus the gene of NuMA, which was repressed in $\mathrm{G}_{0}$ stage rabbit fibroblast, was reactivated and expressed in the pseudo-pronucleus of new reconstructed embryo. Although atypical NuMA distribution in cloned rabbit embryos were observed, normal spindles still formed. The function of NuMA in early cloning embryo development and the relation between NuMA distribution and developmental potential of embryos require further clarification.

Results in this study show that NuMA location is different among rabbit fibroblasts, oocytes, parthenotes, fertilized embryos, and cloned embryos. First, NuMA in meiosis differed within mitosis. It can be observed at every stage during oocyte maturation but disappeared in interphase nuclei of fibroblasts. Second, NuMA in embryonic cells differed with in somatic cell. It exists in interphase nuclei of fertilized and cloned embryos but not in that of fibroblasts. It focuses on the spindle poles of the latter but not on that of the embryos. Finally, the presented data show that there is some variability in NuMA staining for NT embryos as compared with fertilized embryos. We did not observe any NuMA staining in cytoplasm during anaphase and telophase stages in fertilized embryos as in cloned embryos. On the other hand, there are some similarities among them. During the metaphase of fibroblasts, oocytes, or parthenotes, we could detect NuMA at the spindle poles. NuMA may play an important role in spindle pole organization in them. And then, NuMA localization has some similarities between cloning and fertilizing. During metaphase, it did not concentrate on the spindle poles and was absent during anaphase and telophase of fertilized embryos. The reasons for the differences of NuMA distribution, NuMA function, and regulatory mechanisms in the five kinds of objects will require further experimental analysis.

The $\alpha$-tubulin localization during the rabbit oocyte maturation has not been reported. In the present study, we found that cytoplasmic microtubules first appeared around the periphery of the GV. After GVBD, multiarrayed microtubules were found tightly associated with the condensed chromosomes. In fully grown $\mathrm{G}_{2}$-arrested mouse oocytes, several electron-dense condensations from which microtubules radiate have been observed at the periphery of the GV (Szollosi et al. 1972). In pig oocytes, Kim et al. (1996) have reported that microtubules 
are not detected at the GV stage, and that microtubule asters are first observed near the condensed chromatin after GVBD, and microtubules in the meiotic spindle become apparent only during the later meiotic stages.

Similar to the study of Yin et al. (2002), most of the somatic cell nuclei $(87 \%$, 39/45) will undergo PCC when they were fused with non-activated enucleated oocytes and chromosomes in two embryos(2/39) orderly array at metaphase plates and formed a normal transient spindle $4 \mathrm{hpf}$, instead of misaligned chromosome arrays in all embryos as report by Chesne et al. (2002). Within 5-9 hpf, 84\% embryos(27/32) form a swollen pronucleus-like structure.

Compared with our previous data (Yan et al. 2006), following PCC and transient spindle formation, two pronucleus-like structures were found in $68.3 \%$ embryos constructed with monkey fibroblasts and non-activated rabbit oocytes. But only $8.2 \%$ have two pronucleus-like structures when pre-activated ooplasm was used as recipient. These results indicate that the number of pseudo-pronucleus may be influenced by both the donor cell species and the activation administration of recipient oocytes.

In summary, NuMA is involved in meiotic spindle microtubule assembly and spindle pole tethering in rabbit oocytes. However, mitotic spindles can be organized in the absence of NuMA at the poles in cloned rabbit embryos.

\section{Acknowledgements}

This research was supported by the Special Funds for Major State Basic Research Project (001CB509905). The authors thank ShiWen Li for sample scanning and Zhi-Sheng Zhong for technical help. The authors declare that there is no conflict of interest that would prejudice the impartiality of this scientific work.

\section{References}

Almouzni G \& Wolffe AP 1993 Nuclear assembly, structure, and function: the use of Xenopus in vitro systems. Experimental Cell Research 205 1-15.

Becker BE, Romney SJ \& Gard DL 2003 XMAP215, XKCM1, NuMA, and cytoplasmic dynein are required for the assembly and organization of the transient microtubule array during the maturation of Xenopus oocytes. Developmental Biology 261 488-505.

Bredman JJ, Weijs WA \& Brugman P 1991 Relationships between spindle density, muscle architecture and fibre type composition in different parts of the rabbit masseter. European Journal of Morphology 29 297-307.

Chesne P, Adenot PG, Viglietta C, Baratte M, Boulanger L \& Renard JP 2002 Cloned rabbits produced by nuclear transfer from adult somatic cells. Nature Biotechnology 20 366-369.

Compton DA \& Cleveland DW 1993 NuMA is required for the proper completion of mitosis. Journal of Cell Biology 120 947-957.

Fulka J Jr, First NL \& Moor RM 1996 Nuclear transplantation in mammals: remodelling of transplanted nuclei under the influence of maturation promoting factor. Bioessays 18 835-840.
Gaglio T, Saredi A \& Compton DA 1995 NuMA is required for the organization of microtubules into aster-like mitotic arrays. Journal of Cell Biology 131 693-708.

Gaglio T, Saredi A, Bingham JB, Hasbani MJ, Gill SR, Schroer TA \& Compton DA 1996 Opposing motor activities are required for the organization of the mammalian mitotic spindle pole. Journal of Cell Biology 135 399-414.

Gordon MB, Howard L \& Compton DA 2001 Chromosome movement in mitosis requires microtubule anchorage at spindle poles. Journal of Cell Biology 152 425-434.

Han ZM, Chen DY, Li JS, Sun QY, Wang PY, Huang Y \& Du J 2001 The culture of fibroblasts from diaphragm of giant panda. In Vitro Cellular and Developmental Biology - Animal 37 644-645.

Heald R, Tournebize R, Habermann A, Karsenti E \& Hyman A 1997 Spindle assembly in Xenopus egg extracts: respective roles of centrosomes and microtubule self-organization. Journal of Cell Biology 138 615-628.

Kallajoki M, Weber K \& Osborn M 1991 A 210 kDa nuclear matrix protein is a functional part of the mitotic spindle; a microinjection study using SPN monoclonal antibodies. EMBO Journal $\mathbf{1 0}$ 3351-3362.

Kim NH, Funahashi H, Prather RS, Schatten G \& Day BN 1996 Microtubule and microfilament dynamics in porcine oocytes during meiotic maturation. Molecular Reproduction and Development 43 $248-255$.

Latham KE 1999 Mechanisms and control of embryonic genome activation in mammalian embryos. International Review of Cytology 193 71-124.

Latham KE \& Schultz RM 2001 Embryonic genome activation. Frontiers in Bioscience 6 D748-D759.

Lee J, Miyano T \& Moor RM 2000 Spindle formation and dynamics of gamma-tubulin and nuclear mitotic apparatus protein distribution during meiosis in pig and mouse oocytes. Biology of Reproduction 62 1184-1192.

Liu Z, Schatten H, Hao Y, Lai L, Wax D, Samuel M, Zhong ZS, Sun QY \& Prather RS 2006 The Nuclear Mitotic Apparatus (NuMA) protein is contributed by the donor cell nucleus in cloned porcine embryos. Frontiers in Bioscience 11 1945-1957.

Luderus ME, den Blaauwen JL, de Smit OJ, Compton DA \& van Driel R 1994 Binding of matrix attachment regions to lamin polymers involves single-stranded regions and the minor groove. Molecular and Cellular Biology 14 6297-6305.

Lydersen BK \& Pettijohn DE 1980 Human-specific nuclear protein that associates with the polar region of the mitotic apparatus: distribution in a human/hamster hybrid cell. Cell 22 489-499.

Merdes A \& Cleveland DW 1998 The role of NuMA in the interphase nucleus. Journal of Cell Science 111 71-79.

Merdes A, Ramyar K, Vechio JD \& Cleveland DW 1996 A complex of NuMA and cytoplasmic dynein is essential for mitotic spindle assembly. Cell 87 447-458.

Mir B, Tanner N, Chowdhary BP \& Piedrahita JA 2003 UP1 extends life of primary porcine fetal fibroblasts in culture. Cloning Stem Cells $\mathbf{5}$ $143-148$.

Pinto-Correia C, Long CR, Chang T \& Robl JM 1995 Factors involved in nuclear reprogramming during early development in the rabbit. Molecular Reproduction and Development 40 292-304.

Renard JP 1998 Chromatin remodelling and nuclear reprogramming at the onset of embryonic development in mammals. Reproduction, Fertility and Development 10 573-580.

Sun QY \& Schatten H 2006 Role of NuMA in vertebrate cells: review of an intriguing multifunctional protein. Frontiers in Bioscience $\mathbf{1 1}$ 1137-1146.

Szollosi D, Calarco P \& Donahue RP 1972 Absence of centrioles in the first and second meiotic spindles of mouse oocytes. Journal of Cell Science 11 521-541.

Taimen P, Viljamaa M \& Kallajoki M 2000 Preferential expression of NuMA in the nuclei of proliferating cells. Experimental Cell Research 256 140-149. 
Taimen P, Parvinen M, Osborn M \& Kallajoki M 2004 NuMA in rat testis evidence for roles in proliferative activity and meiotic cell division. Experimental Cell Research 298 512-520.

Tang CJ, Hu HM \& Tang TK 2004 NuMA expression and function in mouse oocytes and early embryos. Journal of Biomedical Science $\mathbf{1 1}$ 370-376.

Van Thuan N, Wakayama S, Kishigami S \& Wakayama T 2006 Donor centrosome regulation of initial spindle formation in mouse somatic cell nuclear transfer: roles of gamma-tubulin and nuclear mitotic apparatus protein 1. Biology of Reproduction 74 777-787.

Wakayama T, Tateno H, Mombaerts P \& Yanagimachi R 2000 Nuclear transfer into mouse zygotes. Nature Genetics 24 108-109.

Wilmut I, Schnieke AE, McWhir J, Kind AJ \& Campbell KH 1997 Viable offspring derived from fetal and adult mammalian cells. Nature $\mathbf{3 8 5}$ 810-813.

Yan LY, Shi LH, Sheng HZ, Liu SZ, Huang JC, Zhu ZY, OuYang YC, Lei ZL, Song XF, Sun QY et al. 2006 Dynamic changes in NuMA and microtubules in monkey-rabbit nuclear transfer embryos. Frontiers in Bioscience 11 1892-1900.
Yang CH \& Snyder M 1992 The nuclear-mitotic apparatus protein is important in the establishment and maintenance of the bipolar mitotic spindle apparatus. Molecular Biology of the Cell 3 1259-1267.

Yin XJ, Kato Y \& Tsunoda Y 2002 Effect of enucleation procedures and maturation conditions on the development of nuclear-transferred rabbit oocytes receiving male fibroblast cells. Reproduction $\mathbf{1 2 4}$ $41-47$.

Zeng C 2000 NuMA: a nuclear protein involved in mitotic centrosome function. Microscopy Research and Technique 49 467-477.

Zhong ZS, Zhang G, Meng XQ, Zhang YL, Chen DY, Schatten H \& Sun QY 2005 Function of donor cell centrosome in intraspecies and interspecies nuclear transfer embryos. Experimental Cell Research 306 35-46.

Received 11 April 2006

First decision 13 June 2006

Revised manuscript received 6 July 2006

Accepted 24 July 2006 